\title{
The Letter and the Spirit of the Sendai Framework for Disaster Risk Reduction (a.k.a. HFA2)
}

\author{
Michael H. Glantz ${ }^{1}$
}

Published online: 10 June 2015

(c) The Author(s) 2015. This article is published with open access at Springerlink.com

In the midst of assessing and critiquing the document produced by the World Conference on Disaster Risk Reduction (WCDRR) in Sendai, Japan, I came to realize that we tend to focus on the document itself and less so on the good intentions of many of the delegates and other observers involved in the WCDRR process. Volumes of reports exist expressing this or that approach to redesigning this or that aspect of the Hyogo Framework for Action (HFA) in order to produce an HFA2 to guide voluntary action by governments and practitioners in their disasterrelated activities over the next 15-year period.

\section{The "Letter" of Sendai}

Reviewing many of those interim reports of regional meetings in the run-up to Sendai and accompanying commentary, pro and con, shows a wealth of ideas for a new beginning for HFA2 guidelines for a next-generation disaster risk reduction (DRR) document. But the final draft of the Sendai report then goes to the Sendai organizers to whittle down all that input into a $20+$ page document. By analogy, the end game of producing HFA2 could be likened to a shoe salesperson trying to put someone's size nine feet into size six shoes: nine into six just won't fit and really has no hope of achieving the desired result for the salesperson or for the customer. If purchased, the shoes

Michael H. Glantz

mickeyglantz@hotmail.com

1 Consortium for Capacity Building (CCB), Institute of Arctic and Alpine Research (INSTAAR), University of Colorado, Colorado, CO 80301, USA might be worn on rare occasions with ensuing pain or might have been bought to be kept on a shoe rack for display, maybe as a reminder of when such a shoe did once fit decades earlier. The shoes then become symbolic of some other goal, wearing them daily not being one of those goals.

A statement was produced, the Sendai participants returned home as did the tired negotiators of the wording in the final document. The drafters of the final report did their job: they fit a proverbial size nine foot into a size six shoe, and they accomplished it on schedule.

The organizers got what they wanted, a document filled with suggestions and calls for actions for the next 15 years. It is a very general statement, meeting the wordsmithing demands of those providing input. A word search of HFA (Hyogo) and HFA2 (Sendai, now referred to as SFDRR for the Sendai Framework for Disaster Risk Reduction 2015-2030) shows a remarkable similarity in keywords used in these documents and for the most part in the number of times they were used with a few exceptions. First of all, they are of similar length-20+ pages.

The document will be criticized, without doubt, for what it says and what it does not say. Such a short document could not please everyone within and outside its writing process. So it goes. In order to meet a hard deadline-18 March 2015, the closing of the WCDRR in Sendai, when the powers-that-be at least had to be "satisficed"- that is, unable to produce the "perfect" document for advancing DRR goals, the negotiators opted to produce a document deemed "good enough." They chose not to let the perfect become the enemy of the good. Had they tried for perfect, SFDRR negotiators would still be negotiating, with no end in sight. 
The HFA and SFDRR documents essentially contain the same keywords: climate change (noted 18 times vs. 15, respectively); the acronym DRR ( 24 vs. 0 ); risk reduction (97 vs. 91 ); knowledge (20 vs. 23 ); collaboration (5 vs. 9); prevention (9 vs. 12); partnership (20 vs. 13). The biggest change was for "disaster risk (115 vs. 220) and resilience (22 vs. 33). Cursory comparisons can be made for other terms used in both documents. SFDRR was clearly anchored to HFA, despite the need of and clarion calls for new thinking, for new ideas, for new motivating concepts ("social inventions"), an apparent expanded use of technology (5 vs. 19 [HFA and Sendai, respectively]) and new mandatory commitments. An increased reliance only on new technologies alone-in the absence of new thinkingwill not necessarily get us closer to the "perfect" or improve on the "good enough."

In addition to the words noted, a seemingly insignificant phrase appears throughout both HFA and SFDRR, "as appropriate." "As appropriate" can be viewed as a debatedeflector in a negotiating setting, a safety exit of sorts. In a voluntary document, the "as appropriate" phrase allows even more leeway to governments and organizations to wiggle out of any serious obligation that they might feel impinges on its governance authority or budgetary decisions regardless of the importance of the DRR-related obligations spelled out in SFDRR to protect at-risk people, cultures, and regions in a given country. The caveat "as appropriate" appeared 26 times in HFA and 43 times in SFDRR, almost a doubling of the already built in wiggle room for choosing to abide or not to abide by the wording of the Sendai document.

Most words have multiple meanings. Interpreting words used in a report like that of SFDRR can fuel different, even competing, perceptions and actions about what to do to prepare for foreseeable disasters. Nevertheless, the spirit behind the WCDRR process seems to have been universal and in support of enhanced actions to assure disaster risk reduction efforts are intensified, responsibilities identified, actions taken, and decision-makers held accountable. That spirit of Sendai was most obvious and exemplified by the youth and young professionals who voluntarily engaged throughout the WCDRR process, which many attended at their own expense.

\section{The "Spirit" of Sendai}

Eight-thousand or so attendees to WCDRR and the tens-ofthousands of participants in the run-up to the Sendai conference over the years, along with civil societies worldwide, want and hope for improvements to the way their governments and decision-makers prepare for and respond to disasters. The reasons behind convening a WCDRR are based on hope for a safer future while having to cope with a changing climate. The desire for step-like improvements over "business as usual" DRR efforts is clearly there, though the will to improve will vary from country to country, organization to organization, community to community. The caveat "as appropriate" is, to me, the proverbial "fly in the soup" that allows actors responsible in theory at least for effective DRR to see the SFDRR as a permit to continue along the "business as usual" pathway until the next climate, water, weather, or geohazard reminds them that maybe developing a "culture of prevention" was a more appropriate pathway to have chosen. So it goes.

See you in 2030 at HFA3!

Open Access This article is distributed under the terms of the Creative Commons Attribution 4.0 International License (http:// creativecommons.org/licenses/by/4.0/), which permits unrestricted use, distribution, and reproduction in any medium, provided you give appropriate credit to the original author(s) and the source, provide a link to the Creative Commons license, and indicate if changes were made. 